\title{
Continuous Surface Runoff, Groundwater and Water Quality Modeling of the C-100 Basin, Miami-Dade County, Florida
}

\author{
Tom Nye, Robert E. Dickinson, Michael Thompson, Mike Schmidt, \\ Victor Martin, and Gilberto Peralta
}

C-100 Basin is a 40.6 square mile $\left(105 \mathrm{~km}^{2}\right)$ area in southern Miami-Dade County (Florida) with an approximate elevation range of 5 to $15 \mathrm{ft}$ (1.5 to 4.6 m) NGVD. The basin is an urbanized area of the county, with a western boundary only a few miles from the Florida Everglades, and it drains eastward to Biscayne Bay through the C-100 canal and its tributary canals. There are three control structures in the basin which maintain groundwater levels, provide flood relief, and prevent saltwater intrusion from the bay.

Development in South Miami-Dade County (including the C-100 Basin) has heightened concerns about the impact of stormwater runoff on the quality and quantity of water discharged into Biscayne National Park via the canals in these areas. The primary objective of this planning effort is to improve the quality, quantity and periodicity of freshwater discharges to, and prevent degradation of, Biscayne National Park. Parts II and III of the National Pollutant Discharge Elimination System (NPDES) permit requires implementation of a comprehensive Stormwater Management Master Plan for Miami-Dade County to provide pollutant load reduction and water quantity control by the construction/retrofitting of stormwater management systems. Unique modeling techniques were used in order to accurately calibrate the

Nye, T., R.E. Dickinson, M.K. Thompson, M.F. Schmidt, V. Martin and G. Peralta. 2005. "Continuous Surface Runoff, Groundwater and Water Quality Modeling of the C-100 Basin, Miami-Dade County, Florida." Journal of Water Management Modeling R223-10. doi: 10.14796/JWMM.R223-10.

(C) CHI 2005 www.chijournal.org ISSN: 2292-6062 (Formerly in Effective Modeling of Urban Water Systems. ISBN: 0-9736716-0-2) 
model of the C-100 Basin for both event and continuous simulations. The basin challenges and model solutions are presented in this chapter.

The basin contains extensive areas of French drains that have been designed for the $5 \mathrm{y}$ storm. For other Miami-Dade County basin models, the DCIA had been calculated for each sub-basin and then adjusted to a value based upon the percent of the area covered by French drains. The area containing French drains were assigned 0\% imperviousness. This provided excess infiltration for design storms of higher volumes than the $5 \mathrm{y}$ storm, resulting in the forced calibration of some parameters beyond reasonable values. The solution used for the C-100 Basin was to separate each sub-basin into sub-catchments with and without French drains. The areas with French drains are given $0 \%$ imperviousness, using Horton parameters with a maximum infiltration volume equal to the $5 \mathrm{y}$ storm. The other sub-catchment is given Green-Ampt infiltration parameters and the calculated DCIA.

The basin has substantial lateral groundwater flow through an extremely transmissive aquifer providing baseflow during extreme events that far exceeds the volumes that may be provided using the groundwater routines in SWMM. This baseflow was added to the model using nodes with runoff not linked to the rest of the model, but with groundwater linked to nodes dispersed along the $\mathrm{C}-100$ canal and its tributaries.

The control structures in the basin have operating procedures that are generally determined by headwater stage; however, the rules change from wet season to dry season. The operations of these structures were modeled using combinations of bendable weirs and time-varying orifices.

The basin was simulated for the wet, average and dry year for both the present and future basin conditions for surface runoff, groundwater interflow contribution, canal hydraulics and surface runoff water quality generation and BMP removal. The water quality model of basin C-100 consisted of 14 water quality constituents along with 125 BMPs. The BMPs were simulated using the Transport layer of SWMM. The three existing year models were compared to monitored data using the Nash/Sutcliffe statistic for evaluating model "robustness".

\subsection{Introduction}

The C-100 Basin is the portion of eastern Miami-Dade County that is drained by the $\mathrm{C}-100$ Canal and its tributaries; the $\mathrm{C}-100 \mathrm{~A}$, the $\mathrm{C}-100 \mathrm{~B}$, and the $\mathrm{C}$ $100 \mathrm{C}$. The basin covers an area of approximately 40.6 square miles $\left(105 \mathrm{~km}^{2}\right)$ 
located between the western suburbs of Miami (approximately 2 miles $(3 \mathrm{~km})$ from the Florida Everglades) and Biscayne Bay.

Biscayne Bay is an estuarine resource of unique ecological, recreational, and aesthetic value. The waters of Biscayne Bay include a State Preserve and Biscayne National Park (the only marine park in the National Park System), have been designated "Outstanding Florida Waters", and are thus accorded the highest level of protection possible for Florida surface waters. Development in South Miami-Dade County (including the C-100 Basin) has heightened concerns about the impact of drainage and stormwater runoff, and about the quality and quantity of water discharged into Biscayne National Park via the canals in these areas.

The primary objectives for storm water master plan for the C-100 Basin are to protect Biscayne Bay while providing potential flood control measures for the residents of the basin. In order to meet these objectives, a Storm Water Management Model (SWMM) using XP-SWMM software was developed, calibrated, and used to simulate flood stages, flows, and pollutant loads for event storms and continuous year-long periods.

The South Florida Water Management District's (SFWMD) control structures on the northern and southern boundaries, S-121 and S-122 respectively, are nearly always closed during flood conditions and are treated as no flow boundaries in the model. Structure S-120 is a combination weir and manually operated gate. The gate was generally closed during the calibration periods. Of the remaining three structures, S-118 and S-119 are gated culverts that operate based upon headwater stage. S-118 and S-119 control stages in the upper reaches of the basin and regulate discharges to the lower basin. S-123 is a gated spillway located in the C-100 at Biscayne Bay that controls the stage in the lower reaches of C-100 and regulates discharges to tidewater. A headwater stage is maintained by S-123 adequate to prevent saltwater intrusion into local groundwater. The modeling of the operation of these structures is discussed in a later section.

The C-100 Basin has negligible topographic relief and it is an urbanized area drained by a network of canals. These canals intersect the groundwater table in the unconfined Biscayne aquifer. This aquifer is highly transmissive and provides baseflow to the canals. Land surface elevations range from approximately 4 to $15 \mathrm{ft}$ ( 1.2 to $4.6 \mathrm{~m}) \mathrm{NGVD}$ with most of the C-100 Basin within 7 to $10 \mathrm{ft}(2.1$ to $3.05 \mathrm{~m}) \mathrm{NGVD}$. In the basin a ridge of relatively higher elevations runs parallel to the coast. The canals are located in preexisting valleys cutting through this ridge. Sub-basin delineations within the basin often are developed by the location of roads. 
Average October groundwater levels from 1990-1999 (October, the end of the rainy season, generally produced the highest water table elevations) range from approx. $5 \mathrm{ft}(1.5 \mathrm{~m})$ in the western portion of the basin to $2 \mathrm{ft}(0.6 \mathrm{~m})$ at the outfall.

Flow and stage data were provided by the SFWMD at 15 min intervals at the three control structures for calibration. Rainfall data were available at 15 min intervals at the outfall structure, S-123 and at a gauge (S-338) just west of the western boundary of the model. Hourly rainfall was available at a gauge (556) within the western portion of the basin; however, the data record was incomplete for this gauge. The authors used the program RAINMASTER to distribute the hourly rainfall into $15 \mathrm{~min}$ intervals for the event calibrations. For the continuous simulations, the gauge outside of the basin was used for inland rainfall. Model nodes were assigned inland versus coastal rainfall patterns if the nodes fell west of a 45 degree line intersecting US-1 at the northern boundary of the basin. This distribution was based upon the angle and gradient of the contour lines of storm event volumes as given by the SFWMD.

The design events used for production simulations were the 5-, 10-, 25-, 50- and $100 \mathrm{y}$ storm volumes. To perform the XP-SWMM simulations of these events, the authors used synthetic rainfall hyetographs with total volumes equal those in Table 10.1 below (developed from statistical curve fits for the various return periods), distributed over time using SFWMD standard distributions for southern Florida.

Table 10.1 Rainfall volumes used for production runs.

\begin{tabular}{|c|c|c|c|c|c|c|}
\hline \multirow[b]{2}{*}{$\begin{array}{l}\text { Return } \\
\text { Period } \\
\text { (y) }\end{array}$} & \multicolumn{3}{|c|}{ Coastal Area } & \multicolumn{3}{|c|}{ Inland Area } \\
\hline & $\begin{array}{c}24 \mathrm{~h} \\
\text { Rainfall } \\
\text { Volume } \\
\text { (in.) }\end{array}$ & $\begin{array}{l}\quad 72 \mathrm{~h} \\
\text { Rainfall } \\
\text { Volume } \\
\quad \text { (in.) }\end{array}$ & $\begin{array}{c}\text { Peak } 15 \text { min } \\
\text { Rainfall } \\
\text { Intensity } \\
(\text { in } / \mathrm{h})\end{array}$ & $\begin{array}{l}24 \mathrm{~h} \\
\text { Rainfall } \\
\text { Volume } \\
\text { (in.) }\end{array}$ & $\begin{array}{l}72 \mathrm{~h} \\
\text { Rainfall } \\
\text { Volume } \\
\text { (in.) }\end{array}$ & $\begin{array}{c}\text { Peak } 15 \text { min } \\
\text { Rainfall } \\
\text { Intensity } \\
(\text { in } / \mathrm{h})\end{array}$ \\
\hline 100 & N/A & 14.9 & 7.4 & N/A & 16.3 & 8.1 \\
\hline 50 & $\mathrm{~N} / \mathrm{A}$ & 13.6 & 6.8 & N/A & 14.9 & 7.4 \\
\hline 25 & $\mathrm{~N} / \mathrm{A}$ & 12.6 & 6.3 & $\mathrm{~N} / \mathrm{A}$ & 13.7 & 6.8 \\
\hline 10 & 7.4 & N/A & 5.0 & 8.2 & N/A & 5.5 \\
\hline 5 & 6.3 & $\mathrm{~N} / \mathrm{A}$ & 4.3 & 6.7 & N/A & 4.5 \\
\hline
\end{tabular}

The year-long continuous simulations of wet, average, and dry conditions use realistic patterns of rainfall at $15 \mathrm{~min}$ intervals, which match monthly and annual norms, without having atypical daily volumes. The total annual 
volumes for the typical wet, average, and dry year were found to be 74,64 , and 52 inches $(188,163,132 \mathrm{~cm})$ respectively for the inland portion of the basin. For the coastal portion of the basin, the total annual volumes for the typical wet, average, and dry year were found to be 64,54 , and 45 inches $(163,137,114 \mathrm{~cm})$ respectively.

It is known that rainfall volumes and intensities may vary significantly, both temporally and spatially during storm events in South Florida. The two gauge model of the rainfall is therefore a limitation on the reliability of this model.

\subsection{Model Setup.}

Since the basin is urbanized, most of the area is covered by some form of BMP. Generally, the grassy swales are designed to accommodate the first 0.5 inches $(1.27 \mathrm{~cm})$ of rain. A fraction of this depth was added to the initial abstraction according to the percent swale area per sub-basin. The French drains were designed to accommodate a volume equal to the $5 \mathrm{y} / 24 \mathrm{~h}$ storm, which is approximately 6.5 inches $(16.5 \mathrm{~cm})$. The Hybrid Systems are a combination of French drains and solid pipes connecting to a positive outfall in the canal. In general, the Hybrid Systems were also designed for the $5 \mathrm{y}$ storm and therefore were combined with French drains for runoff modeling purposes (the areas have different pollutant reduction calculations in the treatment layer).

The XP-SWMM hydrologic/hydraulic model uses a node/link representation of the PSMS. Nodes are located at:

- the ends of culverts,

- the ends of equalizers (culverts between adjacent lakes),

- upstream and downstream of bridge structures,

- points along the C-100 canal and secondary canals where the geometry of the channel varies significantly,

- canal intersections,

- the upstream ends of the canals,

- structures along the canals,

- the outfall of the C-100 canal (Structure S-123), and

- points representing the sub-basins' low elevations.

The model contains 286 nodes and 366 links connecting 201 sub-basins, 86 of which are along canals. The sub-basin delineations along the canals are classified into two types. For areas along the canals with drainage systems, 
the sub-basin is wide and contains the drained area. The downstream node within the sub-basin collects the sub-basin runoff and acts as a storage node for the area of the sub-basin that does not include the canal itself. For areas without such drainage, the sub-basin is as narrow as the canal width, and the downstream node is not a storage node.

Runoff from neighboring open sub-basins flows to the canal sub-basin through a link represented by a very short, very wide natural channel with profiles found from elevation data or a nearly flat profile with a depth equal to the height of the canal bank.

The other sub-basin delineations are based upon topographical relief, which generally follows major roadways. Flows between these sub-basins are simulated to occur across very short, very wide natural cross-sections with profiles found from elevation data.

\subsubsection{Adjusting Infiltration Parameters Based upon BMPs}

During the course of designing stormwater master plans for Miami-Dade County, the Dept of Environmental Resource Management (DERM) recognized that the French drain-type BMPs (FDBMPs), in areas where they were abundant, had a significant effect on the directly connected impervious area (DCIA) calculations and therefore model calibration. The FDBMPs, although generally in urban impervious areas, were designed to allow infiltration. The DCIA values could be adjusted to $0 \%$ for these areas, which would be appropriate for the $5 \mathrm{y}$ storms and lesser rainfall events; however, this value is inappropriate for the more extreme events for which the models are often calibrated and for which FEMA relies for flood mapping purposes. The volume of the $5 \mathrm{y}$ storm (6.5 inches in this case) may be added to the initial abstraction; however, this would remove a significant amount of water from the model where in reality this water infiltrates to the groundwater system. Due to the high transmissivity of the Biscayne aquifer, a significant amount of water added to the groundwater system reappears in the canals as baseflow. In order to calibrate to both extreme events and continuous yearlong periods of lesser events without losing water from the system, the authors and DERM developed a two sub-catchment system to accommodate these FDBMPs.

If a given sub-basin was comprised of FDBMP and non-FDBMP areas, the sub-basin was conceptually divided into two subcatchments at the model node by area. All non-FDBMP areas were assigned the DCIA that DERM calculated from percentage of land use type and verified from aerial 
photography. Green-Ampt infiltration parameters were used for these areas (see Section 10.2.2). The FDBMP areas were assigned 0\% DCIA and Horton infiltration parameters were used with a maximum infiltration volume cutoff. The maximum infiltration volume was reduced from 6.5 inches to 5.0 inches during calibration of the model. It is likely that the exfiltration systems (basinwide) are no longer capable of handling their design volume due to age and/or neglect. The other Horton infiltration parameters used in the FDBMP areas were not representative of the soils in these areas. They were instead set to allow full infiltration up to the maximum infiltration volume, and full runoff beyond this threshold.

The division of the sub-basins is conceptual and not strictly physical, as the exact location of the BMP land use was not easily separated from the overall sub-basin. The area was divided and the infiltration parameters and DCIA were different; however, all other runoff parameters including rainfall, groundwater parameters, slope, and flowpath length remained the same. By holding the flowpath length constant, the widths were adjusted to account for the smaller areas.

\subsubsection{Green-Ampt Infiltration Parameters}

The authors developed a global infiltration database, which was adjusted during the calibration of the model, using the Green-Ampt infiltration option. Green-Ampt infiltration and Horton infiltration are two infiltration options available in XP-SWMM for modeling infiltration from pervious areas of watersheds. Horton and Green-Ampt each have three parameters, but the three Horton parameters (maximum infiltration rate, minimum infiltration rate and a decay rate governing the rate of change between the maximum and minimum infiltration rate) are empirical values that are best estimated from calibration to monitored data. Conversely, the Green-Ampt parameters (saturated hydraulic conductivity, capillary suction and initial moisture deficit) are physical parameters that can be measured in the field and estimated using information from the soil triangle. The initial moisture deficit is related to the porosity of the soil.

Horton and Green-Ampt infiltration also have significant differences in how they work in continuous simulation. Horton infiltration, because it is empirical, is dependent on the rate of maximum infiltration regeneration. The maximum amount of infiltration per storm event is a function of the preceding storm intensities, storm inter-event times and the decay rate. The maximum 
rate and minimum rates have to be recalibrated for single event and continuous simulations for these reasons.

Green-Ampt infiltration does not have to be recalibrated for single event versus continuous simulation. The same saturated hydraulic conductivity and suction can be used for yearly simulations as well as day-long simulations. The concerns about initial conditions are alleviated because the program will estimate the value of the initial moisture deficit based on a "warm up" period.

The value used for saturated hydraulic conductivity was $0.4 \mathrm{inch} / \mathrm{h}$ (reduced from the initial value of $0.8 \mathrm{inch} / \mathrm{h}$, see Miami-Dade Aviation Department's (MDAD) Kendall-Tamiami Airport Stormwater Master Plan, CDM, 1995). Although the model is sensitive to this calibration parameter, the authors chose not to vary it too far from the measured initial value. DERM measurements indicate that this value may vary significantly within the C-100 Basin.

Horton parameters were used to mimic the operation of the French drains because the maximum infiltration volume option is only available in XPSWMM within the Horton dialog.

\subsubsection{Modeling of Structure Operations}

The gated inland structures are operated under automatic control based upon headwater elevation. In the following example, for Structure S-118, model depth was measured from the upstream node invert (-10.9 ft NGVD).

When the headwater elevation rises to $4.9 \mathrm{ft}$ (depth of $15.8 \mathrm{ft}$ ) the gate begins to open; when the headwater elevation rises or falls to an elevation of $3.7 \mathrm{ft}$ (depth of $14.6 \mathrm{ft}$ ) the gate becomes stationary; when the headwater elevation falls to $3.5 \mathrm{ft}$ (depth of $14.4 \mathrm{ft}$ ) the gate begins to close.

These control rules were simulated in the XP-SWMM interface by using the Bendable Weir link under the "Special" category of link types. The bendable weir has no flow until a depth of $15.7 \mathrm{ft}$ is reached (a value of zero $(0)$ in the Bend Factor column indicates no flow). The gate opening increased linearly over a 0.2 foot interval to allow the model to be more stable. The gate stayed open until the depth was reduced to $14.6 \mathrm{ft}$ (a value of 1.0 in the Rebound Factor column in the dialog). The gate started to close at a depth of $14.6 \mathrm{ft}$ and was completely closed at a depth of $14.4 \mathrm{ft}$. The rebound factor was linearly interpolated between 14.4 and $14.6 \mathrm{ft}$.

The Bendable Weir special link requires a companion conduit on the same input line in the multi-link dialogue. This multi-link was modeled with a rectangular conduit, $20 \mathrm{ft}$ wide by $13 \mathrm{ft}$ high with inverts at $-5.0 \mathrm{ft}$ NGVD. 
This represents the gate at S-118 in the full open position. To make the model more stable and allow a longer time step, an equivalent length of $100 \mathrm{ft}$ and an equivalent Manning's roughness of 0.008 were used to represent the friction and local losses.

For the gated spillway, Outfall Structure S-123, the operational controls vary from the wet season to the dry season. Therefore, the modeled structure was operated differently in wet weather and dry weather conditions in the continuous models by using a time varying orifice to shift the flow between the wet weather controlled branch and the dry weather controlled branch. The single event production models did not use the opening and closing orifice to choose between the wet and dry weather operating as only the wet weather control was needed.

The node-link representation of this structure was divided into wet weather and dry weather operation branches during continuous simulation. The switch between these branches was based on time varying orifices in the initial links of each branch. If the month of the year was between November 30 th and June 1st, the dry weather operation rules were used by the model. If the month of the year was between June 1st and November 30th, then the wet weather rules were operative.

The time varying orifice opens and closes based on the hour of the year for the continuous simulation models. The continuous simulation orifice when open is $30 \mathrm{ft}$ deep and 900 square $\mathrm{ft}$ in area (to allow total flow), and when closed is 0.0 square $\mathrm{ft}$ in area. The initial wet branch and dry branch links had the same size orifice but varied in the control rule timing. The control rules for the gate operation made the wet operation branch open when the dry operation branch was closed and vice versa. The next link along each branch operated as bendable weirs in the same manner as link S-118. The depths at which the weirs were opened and closed differed depending upon the branch.

The Bendable Weir special link required a companion conduit on the same input line in the multi-link dialogue. The companion conduit was modeled with a natural channel link equivalent to conduit C100-C-21 (upstream of the structure), but with a shorter length.

A rating curve for the outfall structure was supplied to DERM by the SFWMD. Additionally, for both wet weather and dry weather operations, the gated structure at S-123 closes if the difference between the measured headwater and tailwater falls below $0.3 \mathrm{ft}$. Therefore, both model branches required a rating curve control at the actual boundary condition. This control rule was simulated in the XP-SWMM interface by using the Internal Rating Curve link under the "Special" category of link types. This rating curve did 
not allow flow until the difference between the simulated headwater and the stage boundary tidewater was above $0.3 \mathrm{ft}$ (a value of zero (0) in the Flow column). For depths above $0.3 \mathrm{ft}$, the structure's rating curve input. The rating curve does not, by itself, stop flow from Biscayne Bay to the C100 Canal if the tidewater stage is higher than the headwater stage and the weir/orifice system is open; therefore, a flap gate was added to control this relatively rare condition. The flap gate is simulated with a short section of the C100-C-21 canal with the downstream only option turned on.

\subsubsection{Modeling of Groundwater Parameters}

In the C-100 Basin, some of the stormwater discharged to groundwater reappears as base flow (inflow) in the canal system. A portion, however, was lost to the deeper aquifer and removed from the model. The C-100 SWMP model's groundwater parameters, including the deep percolation factor, were calibrated to simulate the division of flow between groundwater base flow and the deep aquifer.

Flow at Station S-118

- - Modeled Flow Observed Flow

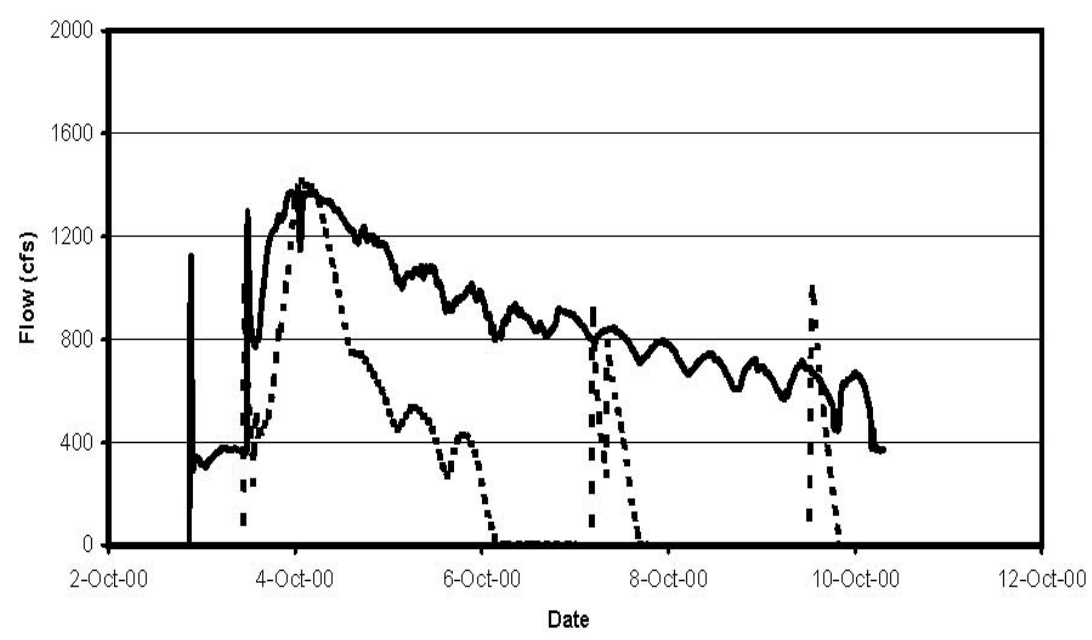

Figure 10.1 October, 2000 initial calibration - no groundwater supply. 
Additionally, regional groundwater flow needed to be accounted for in the model prior to calibration. Figure 10.1 displays modeled flow at Structure S118 versus measured data for the calibration period beginning on October 2nd, 2000 (see 10.3 below) without the regional flow accounted for. This type of result was observed for other large storms for this basin and others within Miami-Dade County. The observed data for the large intensity storms indicate high flow and stage levels which were not accurately calibrated with the groundwater flows from the XP-SWMM interface alone. The data show not only high flow during and directly after the storm, but up to one week after the last of the rainfall. The runoff parameters cannot be adjusted sufficiently to create both the intense peak and prolonged sustenance of the flow and stage elevations, nor can the hydraulic parameters. For instance, the channel roughness may be significantly raised to artificially keep the water high in the receding limb of the simulated stages upstream of the outfall. However, if this flow is essentially backed up, the flow value itself must be too low. If the flows are correct (i.e. high) at the peak of the storm, the recession limbs would necessarily be very sharp as there is a limited amount of rainfall volume over the entire C-100 Basin.

The discrepancy between the observed data and the simulation results achievable with XP-SWMM can be explained by regional groundwater flow. The C-100 Basin is underlain by the Biscayne Aquifer which has measured transmissivities of up to $17 \times 10^{6} \mathrm{GPD} / \mathrm{ft}$. This corresponds to a hydraulic conductivity of over $20,000 \mathrm{ft} / \mathrm{day}$, which is an extraordinarily high value. Essentially, the levels in the canals are very close to the water table height as the transfer of flow is very quick between the two. The extra groundwater flow that the $\mathrm{C}-100$ Basin receives during intense storms is likely due to the regional groundwater gradient from the inland areas west of the $\mathrm{C}-100$ to Biscayne Bay. XP-SWMM is incapable of directly handling this horizontal influx of groundwater as there are no options for the coupled surface water groundwater interactions that are needed. Therefore, the authors developed equivalent "groundwater basins" and associated hydrographs for interflow to the canals from the regional aquifer in an aerial distributed manner. This approach is described below:

Groundwater Flow in XP-SWMM is governed by the following equation:

$$
Q=A_{1}\left(D_{1}-B O\right)^{B_{1}}-A_{2}(B C)^{B_{2}}+A_{3} D_{1}(B O+B C)
$$

where:

$$
\begin{aligned}
D_{1} & =\text { depth of the aquifer (water-table elevation) } \\
B C & =\text { initial depth of the canal (constant) }
\end{aligned}
$$




$$
B O=\begin{aligned}
& \text { canal bottom depth }- \text { base of the aquifer depth } \\
& \text { (constant) }
\end{aligned}
$$

Initially $D 1-B O=B C$, i.e. the water-table depth equals the canal depth

$$
\begin{aligned}
A_{1} \text { and } A_{2}= & \text { calibration coefficients } \\
B_{1} \text { and } B_{2}= & \text { calibration exponents } \\
A_{3}= & \text { typically zero, making the 3rd term not applicable } \\
& \text { (more on A3 later) }
\end{aligned}
$$

The groundwater flow therefore, is a function of water table depth above the initial condition. (There is no negative $Q$ option in XP-SWMM, if $D 1-$ $B O$ falls below $B C, Q=0$ ).

The rise in water-table height, $D$, depends on surface infiltration, the ground water infiltration and percolation parameters as well as the evapotranspiration parameters. The fall of the water-table height is directly proportional to $Q$. Therefore $Q$ is a function of $D$, but $D$ is also a function of $Q$. The water table height is reduced by the following equation:

$$
\Delta D=\frac{-Q}{A \Phi} \Delta t
$$

where:

$$
\begin{aligned}
A & =\text { Basin Area } \\
\Phi & =\text { Porosity, and } \\
\Delta t & =\text { the time step. }
\end{aligned}
$$

Therefore, there is a limited amount of groundwater flow available for a basin for any given rain event. The infiltration rate can be set such that the water table rises steeply; if so, the flow $Q$ will be high, causing the water table to fall sharply as well. Conversely, the porosity can be very small allowing for a very gradual decline in the watertable. This will cause more gradual increases in $D$ as well and $Q$ will be small. There is a finite limit to the area under the flow versus time curve that may be drawn from these equations. Changing the coefficients, exponents, or adding the $A_{3}$ parameter will not increase this amount.

To represent this groundwater flow input as well as possible, the authors has added ground water to evenly spaced nodes along the canal system. The effect of adding these basins is to increase the area term in the Equation 10.2. 
As $A$ is increased, the reduction of the water table elevation is retarded, therefore allowing both high flow and stage for these events.

Figure 10.2 shows the water-table elevations in these wells during the month of October of that year. The $72 \mathrm{~h}$ storm covers the $2 \mathrm{nd}$ through the 5 th days; however, the water table remained elevated well beyond that date. For the inland wells, G-3576, Krome G and G-3559, the elevations had not returned to the initial levels by the end of the month. The more coastal gages all show a return to the initial stages by mid-month. The two wells furthest east, F-319_G and S-182_G rise to near or above the height of the inland wells, and then fall more rapidly. The gradient from west to east is negligible or negative at the height of the storm, then is higher (than the initial condition) on the receding limb of the storm.

In order to add regional groundwater flow on the receding limb of the storms, flow had to be added at the peak as well. The observed data is matched using calibration of the runoff parameters and adjusting the distribution of the groundwater supply areas.

The distribution of the groundwater supply areas was originally evenly dispersed throughout the basin. This distribution was changed during the calibration process as much more flow was needed in the upper reaches of the basin than near the outfall.

\subsection{Model Calibration}

\subsubsection{Event Calibration}

The authors calibrated the C-100 Basin XP_SWMM model to three events. Three storms were chosen with consideration of the limited availability of data (flow, rainfall or gate operation) and to include high intensity events (on order of the 10 to $25 \mathrm{y}$ storm) and a lesser intensity event (on the order of the 5 y storm). For each case, the models were run according to the following criteria:

- The model was run for five days prior to the start date to establish the antecedent moisture condition (AMC), then three days to encompass the storm, then an additional five days to simulate the receding stormwater levels. Once the AMC was established, the results of the first five days of the simulation were later deleted, leaving an 8-day representation of the storm. 
- Only one of the event calibrations will be presented here for brevity. This high intensity storm began on October 2, 2000 at approximately 07:30 hours and is dubbed the "No Name Storm" because the tropical system developed over Florida without becoming a named system.

Groundwater Well Stages

G-3576 $\rightarrow-K R O M E$ G and G-3559 F-319_G $\longrightarrow$-S-182_G -G-757A_G and G-1362_G

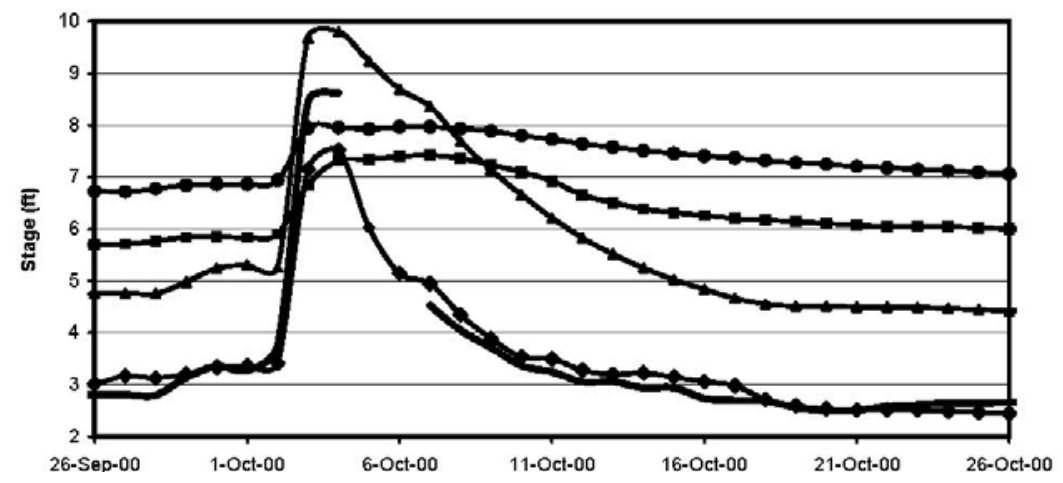

Figure 10.2 October, 2000 Groundwater Levels.

- Rainfall over the inland portion of the C-100 Basin, as measured by gage 536, was 12.89 inches over the three day period. The rainfall over the coastal portion of the C-100 Basin, as measured by gage S-123, was 6.94 inches over the three day period.

- The average of 1990 - 1999 October groundwater levels were used as initial groundwater levels for this simulation. Comparisons of these levels and pre-storm ground water observed data at monitoring wells near the C-100 Basin were favorable.

- In order to mimic the observed stage and flow data, the S-118 structure was modeled to open when the headwater stage rose to $4.8 \mathrm{ft} \mathrm{NGVD}$ and was not closed for the duration of the event. According to the observed stage and flow data, the S-119 structure opened at $4.5 \mathrm{ft}$ and closed at $4.0 \mathrm{ft}$ for the time period preceding the storm. However, at the onset of the storm the structure was opened at $4.5 \mathrm{ft}$ and not closed for the rest of the event. Therefore, to best match the observed data with one operating criteria, the S-119 structure was simulated to open when 
the headwater stage rose to $4.5 \mathrm{ft}$ and was not closed for the duration of the simulation.

- As for most of the other event time periods, the operation criteria for the S-123 Outfall Structure varied over the thirteen day simulation. However, the structure's operation could be approximated by opening the gate when the headwater elevation rose to $3.4 \mathrm{ft}$ NGVD and not closing for the duration of the simulation. The rating curve was used to close the structure or have it remain closed if the difference in elevations between the headwater and tailwater was below $0.3 \mathrm{ft}$.

Figure 10.3 presents the comparison between the simulated and observed flow at the Outfall Structure S-123. Figure 10.4 presents the comparison between the simulated and observed flow at the Structure S-118 (note: contrast this with Figure 10.1, the same comparison, but without groundwater nodes simulating regional groundwater flow). Figures 10.5 and 10.6 compare the simulated and observed headwater stages at Structures S-118 and S-119, respectively.

The difference between total observed and simulated flow volumes at the outfall is $11.9 \%$. The variations in peak flow and peak stage between observed and simulated values are $6.0 \%$ and $1.5 \%$ respectively. For the inland structures S-118 and S-119, differences in predicted peak headwater stages from observed data are $1.6 \%$ and $1.4 \%$ respectively, and the receding stormwater stage is accurately modeled. Two concerns for stormwater management planning are flood levels and durations, for which these predicted peak stages and recession limbs at the upstream nodes show good agreement with observed data.

The modeled and observed flows and stages are not a good match until the bulk of the rainfall from the storm hits. At this point, the modeled gate operations become synchronized with the actual operations. As stated previously, the bendable weir operation depends upon the headwater stage. Small differences between simulated and observed stages may result in significant differences in timing. Human override of the operational procedures also may result in timing differences. Therefore, model calibration is determined by the stage and flow peaks and receding limbs, and the earlier portions of the graph were generally ignored. 


\subsubsection{Continuous Year-Long Calibration}

The model was calibrated to the "average" year conditions as found from statistical analysis. The period with continuous $15 \mathrm{~min}$ data that most closely matched the "average" year was October 1st, 2000 through September 30th, 2001. Rainfall over the inland portion of the C-100 Basin was measured by gauge S-338 and rainfall over the coastal portion of the C-100 Basin was measured by gauge $\mathrm{S}-123$. October groundwater levels were used in this simulation. The simulated conditions become drier during periods of no rainfall due to the deep percolation parameter in the groundwater routine.

Figure 10.7 shows the comparison of simulated and observed cumulative flow as well as mean daily flow for this time period. The difference in total flow volume between the modeled and observed values is $10.1 \%$.

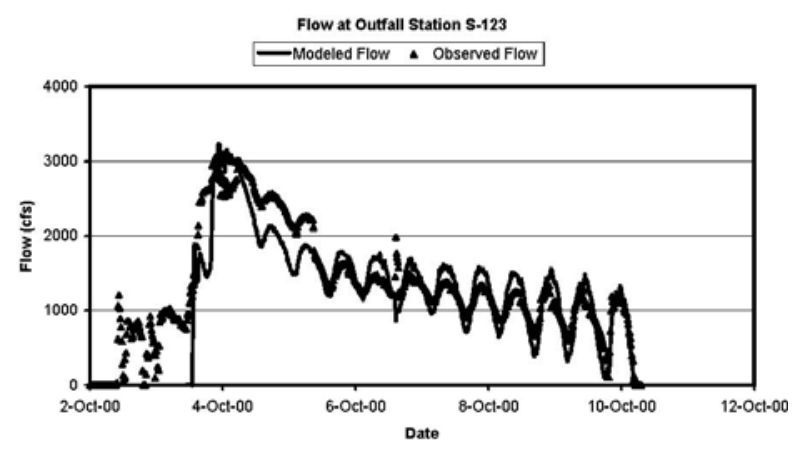

Figure 10.3 October, 2000 final calibration - S-123 flow.

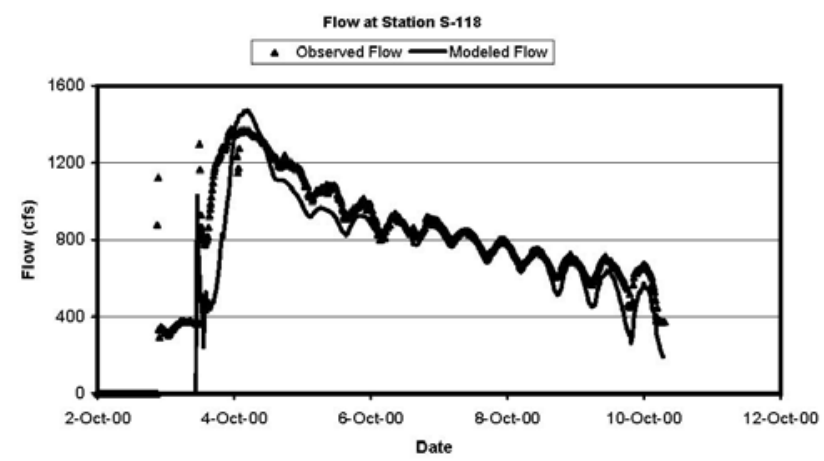

Figure 10.4 October, 2000 final calibration - S-118 flow. 


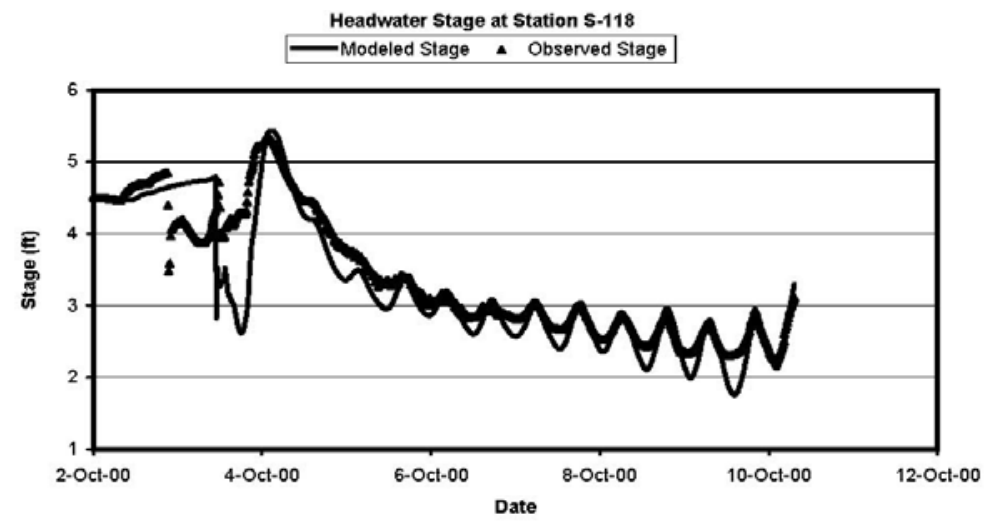

Figure 10.5 October, 2000 final calibration - S-118 stage.

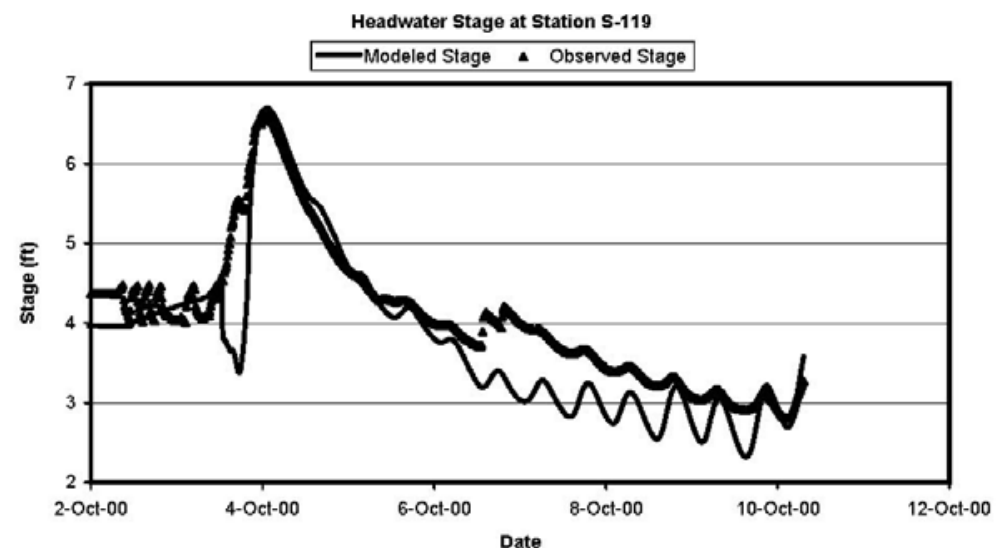

Figure 10.6 October, 2000 final calibration - S-119 stage.

\subsubsection{Nash/Sutcliffe "Likelihood" Measure for Continuous Models}

A single measure of model "goodness of fit" is useful for many reasons. First, it gives a single measure to compare calibration runs, and secondly, it provides a number to rate the model if a stochastic approach is being used. One of the simplest measures is the Nash/Sutcliffe Likelihood Measure (the likelihood that the model results are accurate). It is easy to implement, 
conceptually simple, and provides a good measure of goodness of fit. (Nash and Sutcliffe, 1970)

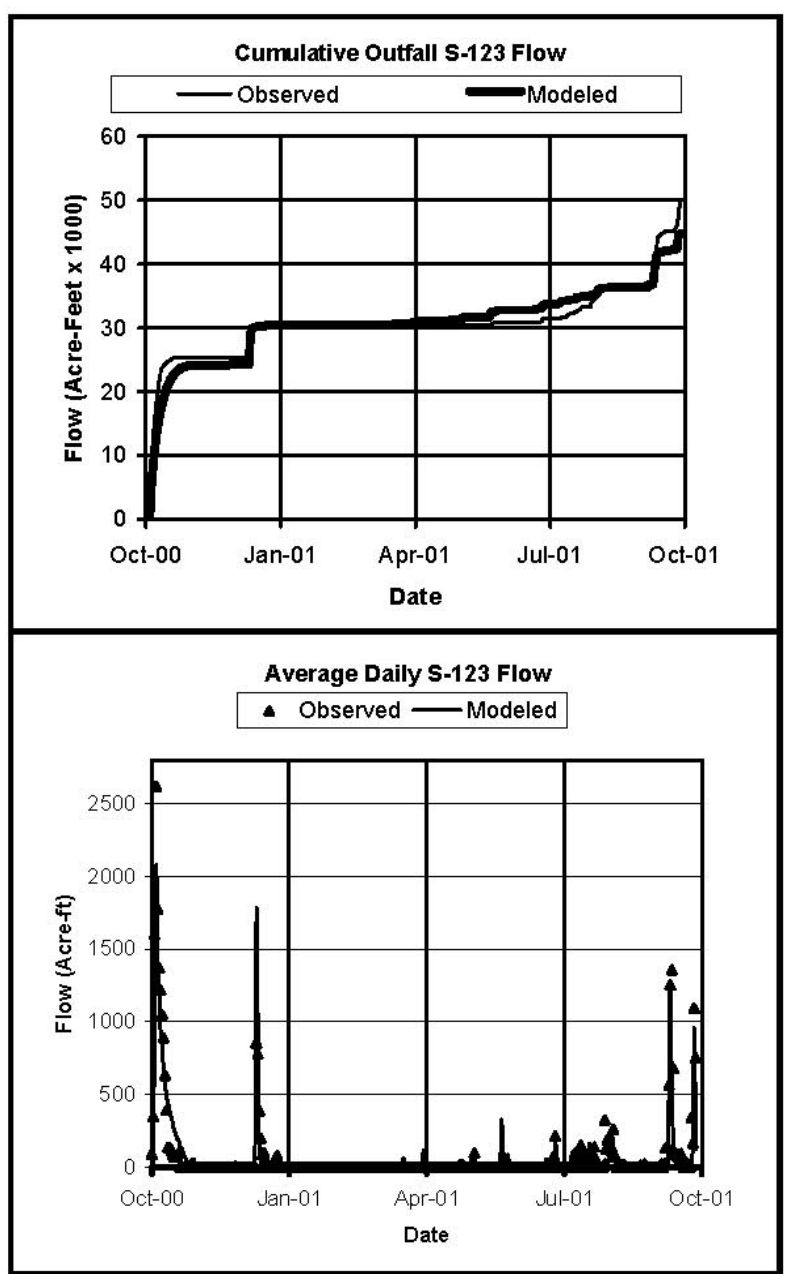

Figure 10.7 Continuous simulation calibration.

The Nash/Sutcliffe method analyzes the model results as an attempt to simulate observed data, with the observed data assumed to be accurate. Thus, 
deviations from observed data are treated as model errors or residuals, even though observed data also have errors which are difficult to quantify.

Nash/Sutcliffe Likelihood Measure "E or Efficiency" uses error (or residual) variance to calculate the model's ability to simulate flows. The Error variance (Var) is sum of squared errors (observed minus simulated).

$$
E=1-\frac{\operatorname{Var}_{e}}{\operatorname{Var}_{o}}
$$

where:

$$
\begin{aligned}
E= & \text { the Nash/Sutcliffe likelihood measure or efficiency } \\
V a r_{e}= & \text { the error variance of the observed data minus the } \\
& \text { modeled data (e.g. observed discharge - modeled } \\
& \text { discharge at } 15 \text { min intervals.) } \\
V a r_{O}= & \text { the error variance of the observed data (e.g. flow) }
\end{aligned}
$$

The measure recognizes that the observed data also has a variance, and takes the ratio of the residual or error variance with the variance of the observed data. In the Nash/Sutcliffe method the higher the efficiency; the better the model is at predicting flows. This method gives results between 0 and 1 for generally acceptable models, less than 0 for poor or "non-behavioral" models. A score of 1 would mean the model was a perfect predictor. A score of 0 means that the model is no better at predicting than using the mean of the observed data as the flow estimation. Although no hard and fast rules are given for an acceptable score, scores above 0.50 to 0.70 should be aimed for.

Note that true confidence intervals or likelihood measures such as Nash/Sutcliffe, although often asked for, cannot really be calculated because they violate basic statistical principals. They assume that:

- the error function mean is 0 : this is probably true in most cases

- the error function has normal distribution: this is rarely or never true

- the variance is constant: this is not true. The variance of errors is often greater for high flows, less for low flows.

- The errors are not correlated: this is not true. For example, prior underestimation of flows in time step, $t$, lead to subsequent underestimations in time step $t+1$. In general, timing problems propagate themselves over the course of the storm. 
The authors performed Nash/Sutcliff calculations on two of the three continuous time periods. The observed data for the "wet" year was incomplete and therefore dismissed.

\section{Dry Year Model}

The continuous dry year model for basin C-100 has a Nash/Sutcliffe value of 0.57 which means that the model does a good job of predicting the dry year flows at gage S-123.

It could be that it is simulating total flows and peak flows with acceptable accuracy, but that the timing of the flow peaks are off because of the model structure. We took the 3-point moving averages of observed and simulated flows intended to investigate how much short term errors in timing might be affecting the model. Using 3-point moving averages reduces the standard deviation from 166 to 152 and the Nash/Sutcliffe value increases to 0.64. Timing does appear to play a role in the dry year continuous model of Basin C-100.

\section{Average Year Model}

The continuous average year model for basin C-100 has a Nash/Sutcliffe value of 0.39 which means that the model does an adequate job of predicting the average year flows at gage S-123.

Again, it could be that it is simulating total flows and peak flows with acceptable accuracy, but that the timing of the flow peaks are off because of the model structure. Using 3-point moving averages reduces the standard deviation from 227 to 200 and the Nash/Sutcliffe value increases to 0.53 . Timing also appears to play an important role in the average year continuous model of Basin C-100.

\subsection{Water Quality}

The water quality calculations use several modules (layers, blocks) of XPSWMM to estimate pollutant generation for a given watershed of sub-basins.

The pollutographs or "massgraphs" generated in the RUNOFF layer were attenuated in the SANITARY layer by pollutant removal factors determined by spreadsheet calculations for 14 indicator pollutants based upon land use and BMP type. The attenuated pollutants were then routed downstream to the 
salinity control structure (outfall structure S-123) using a SANITARY layer routing technique.

Pollutant loads expressed as total load over a time period, for example, $\mathrm{lb} / \mathrm{yr}$, were estimated for all pollutants at the salinity control structure for the 5 design events and the average year continuous simulation. The purpose of generating pollutographs was to determine the timely distribution of loads from the $\mathrm{C}-100$ Basin into Biscayne Bay.

\subsubsection{RUNOFF Layer}

In general, and for the applications presented in this project, the XP-SWMM RUNOFF layer was the origin of water quality constituents.

Buildup and washoff are the most important mechanisms for the simulation of runoff water quality. Over time, it is assumed that an amount of constituents (pollutants) build up on an urban impervious area during dry weather preceding a given storm. When the storm arrives, the material is washed off into receiving stormwater basins by rainfall and runoff dynamics. Washoff therefore is the process of erosion or solutions of constituents from a subcatchment during a period of runoff.

Although several mechanisms exist for the simulation of water quality in the RUNOFF layer, the one chosen in this study was an alternative to the use of the buildup-washoff formulation.

Quality load rates (i.e. mass/time) may be generated by a rating curve approach in which the amount of pollutant being washed off is proportional to the amount of runoff raised to some power. A special case of the rating curve formulation is the Event Mean Concentration (EMC) washoff option, with a power of 1.0 and a coefficient determined from a probability distribution with a given mean and standard deviation. The EMC is assumed to vary with a $\log$ probability distribution, and no buildup is specified in this instance. The EMC is the formulation used in RUNOFF to generate quality parameters for the C100 Basin.

The formulation of water quality procedures in RUNOFF block calls for assigning or apportioning end-of-pipe pollutants concentrations (i.e. EMCs) to a given land use. This scheme implies that a given land use contains several EMCs for each of the several pollutants in question. For example, commercial land use is associated with 14 pollutants, each pollutant with a different EMC value. An array is then formed in which 23 land uses are linked-up with 14 pollutants in such a way that a matrix of 322 elements is formed. Due to lack of data, the standard deviation was set to zero for all land uses and pollutants. 
This matrix became part of the global hydrologic parameters (rainfall, groundwater, infiltration, etc.) initially input into the RUNOFF block. The percent land use for each node/ sub-catchment pair (i.e. sub-basin) was imported to the sub-catchment's water quality data block so that the end result is pollutograph generation at each model node in the RUNOFF Block.

\subsubsection{SANITARY Layer (Treatment)}

The Sanitary (storage/treatment) option in SWMM has the ability of attenuate pollutants either through the use of screening or storage processes. The screening process attenuates pollutants through physical characterization such as settling velocity, particle size and specific gravity or through a user input removal equation in which physical parameters may or may not be involved. Storage processes on the other hand attenuate pollutants by means of quiescent and dynamic settling.

To achieve pollutant loads reduction using the SANITARY Layer in this project, removal factors were estimated for each pollutant in the area of study through the use of spreadsheets. The reduction factors were used in the screening process removal equation, in which the maximum pollutant removal is limited to the reduction factor. The net result was that the pollutographs generated in RUNOFF were effectively attenuated, and discharged into a receiving water body to be routed by a subsequent block in XP-SWMM. Base flow is considered to be "clean" by the SWMM model. This implies that no groundwater flow contributes to pollutants loads; however, whenever groundwater flow is computed and added to the surface water system it may be assigned a given concentration specified by the user.

\subsubsection{SANITARY Layer (Routing)}

The XP-SWMM model currently has the capability to move pollutants in carriage water (by routing pollutant concentration in the flow) using two routing options: the kinematic wave routing and the dynamic wave routing. The kinematic wave routing used by the SANITARY (formerly known as TRANSPORT) layer introduces continuity errors when implemented in territories with predominantly flat slopes and does not recognize boundary conditions. However, small slopes may be given to the conduits in the SANITARY layer in order to have cumulative and peak flows approach the flows simulated by the HYDRAULICS layer. 
The HYDRAULICS layer of XP-SWMM, which uses the dynamic wave routing option, was used in the calibration and production models described previously for water quantity in this report. Ideally, this block would be used to route the pollutant loads to the outfall. Unfortunately, the option was not working properly in XP-SWMM version 8.53 at the time of this project. Therefore, pollutant loads were routed to the outfall using kinematic wave routing in the SANITARY layer.

SANITARY layer routing was accomplished by running two models. In the first model, the RUNOFF and SANITARY (treatment) layers were simulated as described above. The output from the SANITARY layer was written to an interface file just as it would for HYDRAULIC routing. For the second model, the sanitary treatment was turned off (i.e., the loads input from the interface file were not further reduced in the model nodes) and the model links were turned on. The following changes were made to the model link structure in order to route the flow in the SANITARY layer:

- Each conduit was given a slope. Slopes were adjusted to calibrate the flow at the outfall to simulated HYDRAULIC layer flows. It was more important to watch cumulative flows at the outfall than peak flows as cumulative pollutant loads to Biscayne Bay were the primary concern.

- Control structures were removed from the SANITARY router. This layer cannot handle bendable weirs, for example.

- Boundary conditions were removed from the model.

Once the SANTARY layer router was set up, it was used for all production runs. Only the interface file to be read, the start times, and the end times were changed. SANTARY routing has some advantages, including faster run times and easy testing of control measure BMPs (i.e. treatment can be added to the SANTARY router).

\subsection{Conclusions}

This C-100 Basin is a relatively flat, urbanized area in southern Miami-Dade County (Florida) located between the Florida Everglades and Biscayne Bay. The flat topography, the regional groundwater flow through a highly pervious aquifer, the flood control structure operational guidelines, and the numerous BMPs provided a challenging system to model. The authors and DERM collaborated to find unique modeling techniques in order to accurately 
calibrate the model of the $\mathrm{C}-100$ Basin for both event and continuous simulations.

To account for BMPs designed for 5 y storm volumes, the solution used for the C-100 Basin was to separate each sub-basin into sub-catchments with and without French drains. The areas with French drains are given 0\% imperviousness, using Horton parameters with a maximum infiltration volume equal to the $5 \mathrm{y}$ storm. The other sub-catchment is given Green-Ampt infiltration parameters and the calculated DCIA.

The regional groundwater flow was added to the model using nodes with runoff not linked to the rest of the model, but with groundwater linked to nodes dispersed along the $\mathrm{C}-100$ canal and its tributaries.

The control structures in the basin have operating procedures that are generally determined by headwater stage; however, the rules change from wet season to dry season. The operations of these structures were modeled using combinations of bendable weirs and time-varying orifices.

The basin was simulated for the wet, average and dry year for both the present and future basin conditions for surface runoff, groundwater interflow contribution, canal hydraulics and surface runoff water quality generation and BMP removal. The water quality model of basin C-100 consisted of 14 water quality constituents along with 125 BMP's. The BMP's were simulated using the Transport layer of SWMM. Two of the three existing year models were compared to monitored data using the Nash/Sutcliffe statistic for evaluating model "robustness". The results show that the continuous simulations fell within the acceptable category.

\section{References}

CDM, 1995, Kendall-Tamiami Airport Stormwater Master Plan, for Miami-Dade Aviation Department (MDAD)

Nash J.E. and Sutcliffe J.V., 1970, River flow forecasting through conceptual models, a discussion of principles. Journal of Hydrology 10, pp 282-290.) 